\title{
FOUNDATIONS
}

\author{
I'll sound the heights and depths that man can know, \\ Their very souls shall be with mine entwined, \\ I'll load my bosom with their weal and woe, \\ And share with them the shipwreck of mankind.
}

(Goethe, Faust, I)

\section{FOUNDATION AND EDIFICE}

The opening sentences of the Introduction to the Phenomenology draw attention to an assumption that has been shared by philosophers ranging from Descartes to the Wittgenstein of the Tractatus:

It is a natural assumption that, in philosophy, one must first come to an understanding concerning the nature of knowledge before taking up the real subject matter, namely the actual knowledge of what truly is. Knowledge, in turn, tends to be regarded as the instrument with which one takes hold of the absolute or as the medium through which one discovers it. The concern that there may be various kinds of knowledge, of which one might be better suited than another for attaining the end in view, seems moreover legitimate, for by making an erroneous choice among them, one will thus grasp clouds of error instead of the heaven of truth; and when knowledge is taken to be a faculty of a determinate kind and scope, the concern once again seems legitimate that error will be grasped instead of truth unless the nature and limits of this faculty are still more precisely determined. (PG.MM.68/B.131) ${ }^{1}$

Philosophy is concerned with the knowledge of truth, reality, and being, but a central preoccupation of philosophers, since Descartes and Locke, has been with the conditions of knowing rather than the actual content. ${ }^{2}$ This has led, initially, to a desire to determine the limits of human knowledge, to examine the foundations of knowledge before proceeding with the construction of the edifice, a very sound principle in practical matters. If it can be proved that there is a fault in the foundations, it is not essential to examine the edifice brick by brick. This is why Descartes took it upon himself to examine only the first principles of knowledge:

And for that end it will not be requisite that I should examine each in particular, which would be an endless undertaking; for owing to the fact that the destruction of the 
foundations of necessity brings with it the downfall of the rest of the edifice, I shall only in the first place attack those principles upon which all my former opinions rested. ${ }^{3}$

Locke also saw it as his purpose 'to inquire into the origin, certainty, and extent of human knowledge, together with the grounds and degrees of belief, opinion, and assent' ${ }^{4}$ Knowledge, according to Locke, was an instrument which should be 'precisely determined' lest it deceive. As an instrument, it was important to know its limits, just as it is 'of great use to the sailor to know the length of his line', since he may require it to "caution him against running upon shoals that may ruin him'. ${ }^{5}$

Philosophy, held Berkeley, consists solely of 'the study of wisdom and truth', but 'no sooner do we depart from sense and instinct to follow the light of a superior principle, to reason, to mediate, and reflect on the nature of things, but a thousand scruples spring up in our minds. . . .6 $\mathrm{He}$, too, resolved to 'make a strict inquiry concerning the first principles of human knowledge to sift and examine them from all sides... .7 Hume, of course, denied the possibility of explaining the ultimate principles of human knowledge, though he nevertheless held to the same foundational approach as his predecessors when he sought indubitable foundations for the science of man :

And as the science of man is the only solid foundation for the other sciences, so the only solid foundation we can give to this science itself must be laid on experience and observation. ${ }^{8}$

Aroused from his 'dogmatic slumbers' by Hume, Kant, assuming that he required nothing more than 'common logic', undertook a critique of the faculty of human knowledge as a precurser to its employment. Introducing his critique, Kant spoke of the need

to institute a tribunal which will assure to reason its lawful claims, and dismiss all groundless pretensions, not by despotic decrees, but in accordance with its own eternal and unalterable laws. This tribunal is no other than the critique of pure reason. ${ }^{9}$

The initial stages of the twentieth-century 'linguistic revolution' were a variation of the same theme. Instead of a critique of knowledge, Wittgenstein, the foremost exponent of the 'linguistic revolution', advocated a critique of language. Comparing Wittgenstein with Kant, Toulmin writes:

His (Wittgenstein's) central philosophical preoccupations, too, are intelligible (I would argue) only against a Kantian backcloth. Like Kant and Schopenhauer before him, Wittgenstein was eventually preoccupied with the notion of intellectual 'bounds' or 'limits', and with the impulse of the human mind to transcend them. In his arguments Kant's fundamental questions about the scope and limits of reason (Vernunft), 
which had been transformed by Schopenhauer into questions about the scope and limits of representation (Vorstellung), were converted once again into questions about the scope and limits of language (Sprache). ${ }^{10}$

\section{But Toulmin adds :}

In private conversation with Waismann, Wittgenstein talked about these limits (Grenze) and about the human impulse to over-run them (an die Grenze der Sprache anzurennen), in terms which he explicitly compared with Kierkegaard and Heidegger, and which have clear affiliations with the whole tradition of 'critical' or 'transcendental' analysis founded by Kant, and continued throughout all subsequent German philosophy. In the Tractatus Wittgenstein evidently believed that the scope and limits of language - which were also the scope of the intellect, or of thought - could be mapped definitely by applying the techniques and symbolism of Russell's propositional calculus. As the 1920's went on - and especially after 1927, when he began regular discussions with Schlick and Waismann - he gradually lost this confidence. Whereas he had earlier taken for granted the existence of some direct Verbindung der Sprache und der Wirklichkeit, he now acknowledged that some more explicit account was required of the relations between language and the world. ${ }^{11}$

Two questions must be considered by any reader of the Introduction to the Phenomenology: What is the point of mapping out the foundations, or limits, of human knowledge? What are the consequences of a non-foundational approach to the problems of philosophy and the sciences? It will be argued that both Hegel and Wittgenstein rejected the foundational approach and, as a result, numerous parallels can be drawn between their mature works. Of particular concern will be the move from a critique of language (Tractatus) to a description of its use (Blue and Brown Books, and Philosophical Investigations) by Wittgenstein, which is in many ways parallel to the move from a Kantian critique of reason to Hegel's phenomenological description of the various shapes of consciousness in the Phenomenology. Equally important is the movement, by both Wittgenstein and Hegel, from the concept of knowledge as a passive property to the concept of knowledge as an activity to be described as it appears. A study of the Introduction promises, therefore, to provide an understanding of the consequences of rejecting the foundation and edifice theory of knowledge. This should throw light on the differences between Hegel and his predecessors, and also between Wittgenstein's earlier and later writings.

\section{WHAT IS THE POINT OF MAPPING OUT THE FOUNDATIONS, OR LIMITS, OF HUMAN KNOWLEDGE?}

According to the foundationalist, unless a limit was drawn there would be nothing to prevent those metaphysical flights of fancy 
which, from time to time, have showered discredit upon the activity of philosophy. Fear of metaphysical extravagance has led many philosophers to apply a limit to the wanderings of the human mind. Kant held that experience could provide that limit, and likened those who thought they could operate more easily with concepts outside the limits of experience to 'the light dove, who cleaving the air in her free flight, and feeling its resistance might imagine that its flight would be still easier in empty space'. ${ }^{12}$ Similarly, Wittgenstein compared the metaphysician to one who had stepped onto 'slippery ice where there is no friction and so in a certain sense the conditions are ideal, but also, just because of that, we are unable to walk. We want to walk,' he added, 'so we need friction. Back to the rough ground' (PI.107).

Does this mean that, once the limits are fixed, philosophers should abandon the attempt to obtain what Hegel calls 'the actual knowledge of what truly is' - putting out of their minds all puzzlement about the nature of being, reality, and absolute knowledge? Many of Wittgenstein's successors have indeed given up this attempt, concerning themselves solely with the dissolution of philosophical problems, tidying up linguistic or conceptual confusions. This emphasis upon 'philosophic-aversion therapy' lends a certain justification to the question of whether it might be more efficient to invent a pill to cure philosophers of their metaphysical cravings. There is much in Wittgenstein's writings to support this activity, but this would be to misunderstand the nature of philosophy as well as the positive side of Wittgenstein's contribution.

It is true that Wittgenstein saw philosophical questions as the product of certain misconceptions about language (PI.116), and therefore sought to place limits on speculative fantasies. But, like Hegel, he realised that they raised very important questions from which many advances in human knowledge derive their impetus. (Even in the Tractatus, where the limit of language was clearly defined, the importance of what lay beyond this limit was never ignored.) To be puzzled over the nature of absolute knowledge, God, being, immortality, human freedom, life, and so on may be due to certain misleading associations, but unless we have such cravings (including the 'craving for generality' denounced in the Blue Book, p. 17), there would be no knowledge at all. The popular assumption that Wittgenstein directed his efforts solely towards the removal of misleading pictures can blind his readers to the importance of such pictures in the attainment of human knowledge. To deny the relevance of philosophical perplexity is to misunderstand the nature of 
the relationship between philosophy and the various sciences. Consider, for example, how certain mathematical statements have given rise to philosophical perplexity, but without this perplexity advances within mathematics would not have been made. Says Wittgenstein :

Certain verbal forms are misleading for a time and then cease to be misleading. The idea of imaginary numbers, e.g. There may have been something misleading in this when it was first introduced but now it is utterly harmless; it just does not mislead anyone, while to say that the appellation 'infinite development' is misleading is correct, though of course it does not mislead anyone in his calculations. It misleads in the idea of what they have done and the consequent interest which people have in certain calculations. The idea of the infinite as something huge does fascinate some people and this interest is due solely to that association, though they probably would not admit it. But that has nothing to do with their calculations. We could, e.g., play chess without the board or chessmen, by description of the moves, etc. I might say that chess would have never been invented apart from the board, figures, etc., and perhaps the connection with the movement of troops in battle. No one would have dreamed of inventing the game as played with pencil and paper. That would be right, but still the game (as played either way) would not be wrong. It is the same with mathematics. There is nothing right or wrong in a calculus, but it is the associations which make it seem worthwhile. But they are quite different from the calculus. Sometimes the associations are connected with practical applications; sometimes they are not. The association with the infinite is with something huge. Without this association no one would care a damn about the infinite. ${ }^{13}$

Wittgenstein's point is that the sciences are permeated with philosophical questions which enjoy a different logical status to other questions arising within each science. For example, mathematicians, argues Wittgenstein, have been puzzled over the nature of the infinite and have sometimes conceived it in terms of a large number. Against this view, Wittgenstein would argue that the infinite is not a number at all, but the expression of a rule which allows one to say 'I can go on'. But unless people saw the infinite as puzzling, there would never have been any strides in the history of mathematics. True, the infinitesimal calculus does not tell us anything about infinitesimal objects, but puzzlement about infinitesimal objects has led to mathematical developments. A similar case can be made concerning the relationship between philosophy and other sciences. Philosophical perplexity concerning the nature of matter, life, energy, soul, and mind has been the driving force behind scientific discovery. ${ }^{14}$

To be sure, the sciences do not answer the philosopher's questions - though developments in the sciences may remove some of his puzzlement - for he is concerned with the nature of reality, which belongs to another dimension of human experience. ${ }^{15}$ And, 
according to Hegel, philosophical puzzlement is not satisfied with empirical findings, because the former belong to an infinite sphere of human experience:

In its own field this empirical knowledge may at first give satisfaction; but in two ways it is seen to come about. In the first place there is another circle of objects which it does not embrace. These are freedom, spirit, and God. They belong to a different sphere, not because it can be said that they have nothing to do with experience; for though they are certainly not experiences of the senses, it is quite an identical proposition to say that whatever is in consciousness is experienced. The real ground for assigning them to another field of cognition is that in their scope and content these objects evidently show themselves as infinite. (Enz.I.8)

Hegel is not putting forward an argument for a strict demarcation between philosophy and the sciences. On the contrary, he argues very strongly that philosophy 'owes its development to the empirical sciences', and in return 'it gives their contents what is so vital to them, the freedom of thought, - gives them, in short, an a priori character' (Enz.I.12). His account of the relationship between the respective 'spheres' of philosophy and the empirical sciences can be understood with reference to R. Bambrough's use of the analogy between pure and applied science. ${ }^{16}$ Whilst they are logically independent of each other, says Bambrough, they are not mutually irrelevant. So, he argues, with philosophy the application of the propositions of pure philosophy is logically distinct, but not irrelevant to the propositions of 'applied philosophy'. Hegel's point about philosophy giving an a priori character to the empirical sciences is aptly illustrated in the following remark by Bambrough:

The techniques and the results of the pure philosophy are also capable of being applied to the treatment of non-philosophical questions. The pure a priori principles that are elicited and enunciated by the pure philosopher are the principles which are used by thinkers about non-philosophical questions: by scientists and historians and moralists and theologians and critics.

The most striking cases of the application of the methods and principles of pure philosophy to the treatment of non-philosophical questions are found in the work of radical innovators who are reassessing and calling into question the most fundamental concepts of their own disciplines. Freud was concerned with questions about the nature of the human mind. His study was an empirical study, a study of the actual, of man as he is. But in the course of pursuing this study he found it useful to reflect on the a priori philosophical questions 'What is a wish?' or 'What is the unconscious state of mind?' or 'Is it conceivable that there should be such a thing as an unconscious state of mind?' When he reflected on these and similar questions he was reflecting philosophically: he was not only using the techniques of the philosopher, but using them on questions that belong to pure philosophy. But he was doing philosophy with a view to making progress in psychology, as the engineer and the physicist do mathematics with a view to solving problems or making discoveries in engineering or physics. ${ }^{17}$ 
The relationship between philosophy and the empirical sciences has given rise to much confusion in philosophy. Propositions belonging to the sphere of 'pure philosophy' have often been misconstrued as statements of empirical fact. We might say that Kant's Critique and much of Wittgenstein's writings represent an attempt to show where metaphysicians had mistakenly thought their utterances to be scientific. (This is not to be confused with the positivist attempt to consign metaphysics to the flames, since positivism itself entails many dubious metaphysical assumptions.) Kant, especially, saw the Critique as a preliminary to giving satisfactory answers to metaphysical questions such as the justification for belief in God; the nature of human freedom, immortality, and the good life. One might say that the need to resolve genuine philosophical problems justifies the critical approach: those who see the destruction of philosophy in a critique have missed the point of philosophy.

We can see, then, how the 'mapping out' of the bounds of human knowledge can serve to emphasise either that which lies within the boundary or without. The latter, the metaphysical (or ethical), can be just as important from the standpoint of the critique. This is why Wittgenstein considered that his most important work was unwritten. ${ }^{18}$ His own puzzlement, in the Tractatus, concerning the nature of the good life (6.421), immortality (6.4311), the 'why of the world' (6.44), the problem of life (6.52), and even the propositions of the critique itself (6.54), was considered unsayable.

The Tractatus was, broadly speaking, an attempt to undertake, in the manner of Kant, a once and for all critique of language. Language was examined instead of thought in order to avoid any 'inessential psychological investigations' ${ }^{19}$ but in both cases the objects under investigation were the conditions for the attainment of human knowledge. Having examined the conditions of knowledge, one could then decide what could be done with them.

The answer to the initial question, in this section, must be that the point of a foundational approach can only be to provide the conditions believed necessary for the isolation of the philosophical sphere of experience. In Hegel's terms, this would be 'the attainment of' absolute knowledge.

Before answering our second question - What are the consequences of rejecting a foundational approach? - we must understand why Hegel rejected it. It is necessary, however, to anticipate some of Hegel's conclusions in order to understand how he undermines the foundational approach, since he is at an advantage over his reader, having allready recognised the consequences of his rejection before presenting it in its publishable form. Hegel was the first 
philosopher to question the intelligibility of a critique, and to reject the assumption that the foundations of human knowledge, or indeed any of the sciences, could be examined as a precursor to their active employment. Like the later Wittgenstein, Hegel saw human knowledge as an activity to be described, as it appears, rather than a passive object to be examined in isolation from its content. Hegel's method is therefore descriptive, and how better can one begin a descriptive method than with a phenomenological account of the above-mentioned assumptions of Descartes, Locke, Berkeley, Hume, Kant, and Wittgenstein of the Tractatus? The Introduction is not an introduction to a system, still less a synopsis of an alleged dialectical method. There can be no introduction to a purely descriptive phenomenology of human consciousness, just as there can be no introduction to experience. ${ }^{20}$ Instead, the Introduction, in keeping with the method employed throughout the subsequent chapters, is an attempt to take seriously the kind of assertions with which philosophers have usually prefaced their works. ${ }^{21}$ If this is the case, then what is the point of writing an Introduction? Why not simply begin with the first chapter?

\section{WHAT IS THE POINT OF AN INTRODUCTION?}

The Introduction marks a break with the traditional ritual of examining the foundations of knowledge. Hegel suggests that consciousness stands in an immediate relation to its object - in the case of philosophy, the absolute. The purpose of the Introduction is therefore to break down the artificial distinctions between knowledge and its object. The natural state of man, implies Hegel, is to be in the presence of the absolute. This is a condition of there being any knowledge at all, since philosophical puzzlement is bound up with advances in the various systems of knowledge and is concerned with the nature of absolute knowledge. This is not to say that philosophy is, in some way, a foundation for the sciences. Philosophical puzzlement only occurs when a considerable body of knowledge is already established. Absolute knowledge, the object of philosophy, is a presupposition of the various sciences. For this reason, we cannot be introduced to a means of taking hold of it any more than we can be introduced to language, which is itself both a product and a condition of scientific development.

What is the traditional conception of the absolute? As we have seen in the remarks of Descartes, Locke, Berkeley, Hume, Kant, and Wittgenstein of the Tractatus, if the absolute is not nonsense to be 
put out of mind, it is something that can be approached after a critique of human knowledge, or language. We must therefore consider Hegel's description of these assumptions held by critical philosophy.

\section{THE LOGICAL CIRCLE OF CRITICAL PHILOSOPHY}

Critical philosophy involves a distinction between the means of knowing and what is known. This arises from a desire to be certain that what emerges will be the truth. The trouble with this procedure is that the critique itself claims to be knowledge; that is, something which we can know. If we can only achieve this knowledge by an act of knowledge, then how can we examine the primary act of knowledge? How can we examine the cognitive faculty? In The Logic of $\mathrm{Hegel}$, he expresses the problem as follows:

A main line of argument in the Critical Philosophy bids us pause before proceeding to inquire into God or into the true being of things, and tells us first of all to examine the faculty of cognition and see whether it is equal to such an effort. We ought, says Kant, to become acquainted with the instrument before we undertake the work for which it is to be employed; for if the instrument be insufficient, all our trouble will be spent in vain. The plausibility of this suggestion has won for it general assent and admiration; the result of which has been to withdraw cognition from an interest in its objects and absorbtion in the study of them, and to direct it back upon itself; and so turn it into a question of form. Unless we wish to be deceived by words, it is easy to see what this amounts to. In the case of other instruments, we can try to criticise them in other ways than by setting about the special work for which they are destined. But the examination of knowledge can only be carried out by an act of knowledge. To examine this so-called instrument is the same thing as to know it. But to seek to know before we know is as absurd as the wise resolution of Scholasticus, not to venture into the water until he had learned to swim. (Enz. I.10)

Every consistent foundational epistemology is trapped in this logical circle from the beginning. The critique of knowledge, as Habermas says, does not possess the spontaneity of an origin; it is condemned to being after the fact. ${ }^{22}$ As such, there are no first principles, whether ultimates of sense or the self-defining cogito, but this does not mean that knowledge cannot be made a subject for analysis. Indeed, Hegel even considers that a 'very important step' was taken 'when the terms of the old metaphysic were subject to scrutiny' (Enz.I.41.Zu.). The Kantian demand for a criticism of the faculty of cognition as a preliminary to its exercise, Hegel regarded as a 'fair demand if it meant that even the forms of thought must be made an object of investigation' (Enz.I.41.Zu.). ${ }^{23}$ Unfortunately, 'there soon creeps in the misconception of knowing before you 
know - the error of refusing to enter the water until you have learnt to swim. True indeed, the forms of thought should be subjected to a scrutiny before they are used : yet what is this scrutiny but ipso facto a cognition' (Enz.I.41.Zu.). The error lies in conceiving of the faculty of cognition as a distinct entity which can be examined in its passive state, as a 'preliminary to its exercise' (Enz.I.41.Zu.). That is to say, foundational epistemology conceives of an external distinction between means (cognition) and ends (knowledge).

One of Hegel's points is that foundational epistemology has failed to grasp how, in an important sense, knowledge is bound up with certain activities, and it is for this reason that it cannot be examined as a 'preliminary to its exercise'. Consider the type of distinction Ryle has drawn between 'knowing how' and 'knowing that'. Knowing how to swim, for instance, is different to knowing that the swimming-baths open at 9.30 A.M., the depth of the water, and so on. One cannot sit down and record all the things that one knows, since very often the criterion of knowledge is bound to performance. Hegel's criticism of foundational epistemology therefore ushers in a new concept of knowledge: if knowledge is bound to performance, then an examination of the faculties of cognition, as a preliminary to their exercise, is impossible. This touches on a fundamental difference between Hegel and Kant. It is true that, for Kant, unlike Locke, Berkeley, and Hume, cognition was an active process - this can be seen in his arguments concerning the 'unity of apperception'. But Hegel's point is that in certain respects knowledge is creative, and cannot be assessed apart from performance. Kant, however, held that whilst knowing was an activity, the faculties which perform this activity could be examined independently, and 'knowing before you know' could therefore be equivalent to knowing the possibilities before the actual event, or knowing the rule prior to its application. This Hegel denied, since in those cases where knowing is bound to performance, the criterion for knowing always follows the deed. This anti-foundational approach found expression in Goethe:

Tis writ, 'In the beginning was the Word'.

I pause, to wonder what is here inferred.

The Word I cannot set supremely high:

A new translation will I try.

I read, if by the Spirit I am taught,

This sense: 'In the beginning was the Thought'.

This opening I need weigh again,

Or sense may suffer from a hasty pen. 
Does Thought create, and work rule the hour, 'Twere best: 'In the beginning was the Power'. Yet, while the pen is urged with willing fingers, A sense of doubt and hesitancy lingers.

The spirit comes to guide me in my need, I write, 'In the beginning was the Deed'.

$(\text { Faust }, \mathrm{I})^{24}$

One may examine a person's intention to swim the Channel, and we can examine his physical fitness, but whether he knows how to swim the Channel can only be determined by reference to his actual performance. Whereas Kant attempted to analyse the contents of cognition before their employment, Hegel demanded that we

combine in our process of inquiry the action of the forms of thought with a criticism of them. The forms of thought must be studied in their essential nature and complete development: they are at once the object of research and the action of that object. (Enz.I.41.Zu.)

The logical circle of 'knowing before you know' does not imply that we cannot examine and criticise what is allegedly known. If that were the case, anything would count as a truth and we would merely repeat the mistakes of the pre-Kantian metaphysicians. Contrary to what many commentators hold, Hegel's rejection of the Kantian critique was not an attempt to resurrect pre-Kantian metaphysics or unlimited rationalism. ${ }^{25}$ Instead the emphasis of criticism falls not on the structure of the cognitive faculties, but rather on the action of knowledge as it expresses itself in the world. The logical circle applies only to attempts to measure and evaluate the foundations of knowledge from an external standpoint.

\section{REINHOLD'S ATTEMPT TO BREAK THE LOGICAL CIRCLE: DYNAMIC FOUNDATIONS}

One might think that the circularity of 'knowing before you know' can be avoided by conceding that the critique begins with presuppositions which are primarily problematic, but in principle can be verified by subsequent investigation. This 'problematic' method, originally adopted by Reinhold, ${ }^{26}$ is still very popular in Popperian circles. This version does not advocate that all its principles are problematic. On the contrary, the set of presuppositions which defines the frame of reference of a given investigation should be assumed as unproblematic during the course of the investigation. 
But then the logical circle returns: How do we know which principles we are to consider as unproblematic? What standard do we employ? Sir Karl Popper stands in a similar position to Reinhold when, after rejecting the concept of absolute foundations, he opts for dynamic foundations. And like Reinhold, he is wedded to the foundation and edifice theory of knowledge:

The empirical basis of objective science has thus nothing 'absolute' about it. Science does not rest upon solid bedrock. The bold structure of its theories rises, as it were, above a swamp. It is like a building erected on piles. The piles are driven down from above into the swamp, but not down to any natural or 'given' base; and if we stop driving the piles deeper, it is not because we have reached firm ground. We simply stop when we are satisfied that they are firm enough to carry the structure, at least for the time being. ${ }^{27}$

Dynamic foundations, however, do not eliminate the regress into the logical circle of 'knowing before you know'. The piles sunk into the swamp, which, according to Popper, are analogous to 'basic statements', are the foundations upon which the edifice of knowledge may rest.It is true, he admits, that they can shift; they are dynamic foundations. But, as in the case of the building on the swamp, we can only know whether the foundations are secure by reference to the size of the building which is to be erected upon them. Taking Popper's view seriously, we can know nothing of the building until the foundations are laid, since the foundations determine what can be built on them. But the foundations - which are to give us knowledge of the type of building we can have - require a certain amount of knowledge of the building before we can decide whether they are adequate to lay the first brick on them. Similarly, with science and knowledge: basic statements, however dynamic, require some reference to that which is to hang on them. This is what Wittgenstein means when he says:

It is not single axioms that strike me as obvious; it is a system in which consequences and premises give one another mutual support. (OC.142)

Hegel's treatment of the 'problematic' method, however, consists of an application of its inherent scepticism to accounts of the emergence of knowledge. Every foundationalist theory of knowledge betrays a lack of confidence in unfounded statements, so taking this view seriously, Hegel questions the convention of assigning some statements as unproblematic. Why these and not others? A critique aimed at the whole compass of human knowledge has no justification for sparing some statements, unless it has some prior knowledge. In which case the logical circle reappears. For this reason, argues Hegel, Reinhold's 'hypothetical and problematic' method does not 
escape the logical circle of 'knowing before you know'; his correct insight into epistemology's circularity 'does not alter the character of the method', says Hegel, 'it only makes clear its imperfections' (Enz.I.10).

\section{THE FEAR OF ERROR}

The pursuit of the incorrigible is one of the most venerable bugbears in the history of philosophy. (J.L. Austin) ${ }^{28}$

If, as Hegel argues, the critique of the foundations of knowledge is circular, does it follow that giving up the attempt to determine the foundations should entail giving up the critical method altogether? Surely the critical philosopher has only to abandon the circular position of claiming knowledge before it is achieved? The problem arising from the critical method, however, is that there is no limit to the radical scepticism which is built into the attempt to construct a critique of human knowledge. How is it to get started when we cannot discover a principle, or standard, which is not subject to scrutiny and doubt? This is the kind of position that Wittgenstein was thinking of when he asked:

If the shopkeeper wanted to investigate each of his apples without any reason, for the sake of being certain about everything, why doesn't he have to investigate the investigation? (OC.459)

Cannot all standards be treated as arbitrary in the absence of the initial knowledge necessary to establish them? According to Hegel, the presence of scepticism affects the whole epistemological approach:

If concern about falling into error makes one in the meanwhile distrustful of science, which goes to work and actually knows without any such hesitations, then one should not overlook the possibility of reversing this procedure by placing distrust in this very distrust and becoming concerned about another question: Is not the fear of error already the error itself? In fact this fear presupposes a great deal as truth; its hesitations and inferences are based on an assumption whose claim to truth is yet to be examined. (PG.MM.69/B.132-33)

If critical philosophy is to be taken seriously, the presuppositions built into the critique must be subjected to radical doubt. Thus, if the critical philosopher adopts a principle of mistrust, then this principle cannot be limited. If all standards must be examined, we must be prepared to include the principle of scepticism entailed by this programme of criticism.

From the standpoint of philosophy, as we have noted, the purpose 
of a critique is to determine whether consciousness can even take hold of the absolute. In the above quotation, the term 'science' must be taken to refer to philosophy. When Hegel says that science 'actually knows without any such hesitations', he is hinting at a distinction between the science of philosophy, which has an internal relation to its object (the absolute), and the other sciences, whose object may be externally related. To rush in without any examination of the means of taking hold of the truth is, in any other science, to run the risk of error. Unless the telescope is examined from time to time, we cannot have certain knowledge concerning the astronomer's observations. But we can only speak of error when we have some knowledge of the object; we can only know whether the telescope is wrong if we have independent knowledge of the phenomena observed by it. In the case of philosophy, to speak of error would presuppose an independent knowledge of the absolute. Yet this is precisely what is denied by those who suggest an examination of the means in order to avoid erroneous speculation about the absolute. Thus the error committed, in this case, is the 'fear of error itself'.

The mistaken assumption, at which Hegel's reference to 'knowing without hesitation' is directed, is of an absolute that stands on one side - out there - independent of the means of taking hold of it,

but above all, it presupposes that the absolute stands on one side and that knowledge, though it is on the other side, for itself and separated from the absolute, is nevertheless something real. (PG.MM.70/B.133)

The distinction between knowledge and the absolute, claims Hegel, rests on an unwarranted dogmatism. Knowledge of the absolute is not determined by the application of a critique, since any critique which ruled out the possibility of such knowledge could always be rejected as inadequate. Ironically, the only critique exempt from further criticism is that which confirms the possibility of absolute knowledge. This can be illustrated by reference to certain problems concerning the existence of viruses. Before the invention of the electron microscope in the 1940s, there were no adequate means of observing them, which placed considerable strain on the intelligibility of speaking of living agents no larger than some chemical molecules. Nevertheless there were scientists who became convinced of the existence of viruses, and the failure to observe them by means of the conventional microscope served only to reveal its inadequacy for the task. The virus 'paradigm', we might say, was too deeply entrenched for it to be refuted by observations based on the conventional microscope. On the other hand, scientists were 
willing to accept the evidence of the electron microscope, which revealed that viruses were from half to a quarter the size of a wavelength of violet light, which, incidentally, explained why the conventional microscope was inadequate. But by that time so much was known about their shape and size that nothing new was revealed. ${ }^{29}$ In short, the idea of viruses as living agents was such that the only observational criterion acceptable to the scientists was that which confirmed their hypothesis.

It is the same with a critique designed to prove whether or not absolute knowledge lies beyond the limits of human attainment. A critique which argues that the absolute lies beyond the limits of knowledge can always be dismissed as unsatisfactory, since it is always possible that someone will develop the appropriate methods for taking hold of it. Ultimately, the only unproblematic critique is that which acknowledges the reality of the absolute and can be independently tested by reference to knowledge of the absolute. But this presupposes that the absolute is already known. So when Hegel suggests that 'science knows without hesitations', he is hinting that the absolute is present all the time - a precursor of the conclusion of the Phenomenology, where the absolute pervades all knowledge.

\section{THE ORGANON THEORY OF KNOWLEDGE: KNOWLEDGE AS A MEDIUM OR INSTRUMENT}

Critical philosophy, as we have observed, assumes the intervention of the means of knowing between consciousness and what it knows. Hegel's next move is to develop the nature of this assumption. To those who adhere to the assumptions of critical philosophy, cognition is assumed to be an organon, or instrument, in Aristotle's sense. To break the hold of this picture, Hegel seizes on a metaphor beloved by epistemologists: knowledge is mediated, either by an instrument or a medium; the former shaping what is known, the latter serving as a filter for what is received from the outside. What both views hold in common is the assumption of an intervening factor between the knowing subject and its knowledge. Hegel's point, however, is that once we take seriously the idea that cognition stands between consciousness and the absolute, then any form of knowledge will prove inadequate to its task. This implies that any attempt to know the absolute, on these terms, will prove to be an absurd undertaking: an objection which applies to both conceptions of knowledge as an instrument or medium. 
The metaphor of an instrument suggests that knowledge is something employed and manipulated, whilst the metaphor of a medium suggests that it is passively received. Both are held to affect the knowledge actually received. Neither forms an adequate means of cognition equal to the knowledge sought, since their contribution somehow prevents one from grasping the absolute as it is :

For if knowledge is the instrument to take hold of the absolute essence, one is immediately reminded that the application of an instrument to a thing does not leave the thing as it is, but brings about a shaping and alteration to it. Or if knowledge is not an instrument for our activity, but a more or less passive medium through which the light of truth reaches us, then again we do not receive this truth as it is in itself, but as it is in and through this medium. (PG.MM.68/B.131)

Hegel is here characterising the critical philosopher as one who attempts an examination of the instrument or medium in order to distinguish its contribution from what is derived objectively from the 'external world'. In other words, critical philosophy must try to eliminate the contribution of the instrument or medium in order to discover the absolute in itself.

We can illustrate this point with the following examples:

$A$. The examination of knowledge as an instrument is akin to the examination of an instrument with which one obtains knowledge of various phenomena in the sciences. Consider a scientist who has isolated a single organism on a laboratory slide. He observes it through his microscope in order to discover certain facts about it, but his knowledge of the organism will be incomplete in one important respect, since the artificial conditions of the laboratory constitute a limitation on his knowledge of the organism. The instrument, seen as a means of obtaining knowledge, also contributes to and distorts the object ; instead of a living organism, freely interacting with its environment, the scientist observes a laboratory artefact. If the scientist were one who subscribed to the views of critical philosophy, he might think that a perfect knowledge of the organism can only be obtained if, somehow, the contribution of his instruments is deducted. But the instruments, we remind him, are the only means by which the organism is known. Likewise with the absolute: to eliminate the instrument is to exclude the possibility of knowledge of the absolute. This position is unavoidable if one maintains that philosophical knowledge and its object are externally related.

$B$. If one holds the metaphor of knowledge as a medium, the problem is similar. Consider how the argument from illusion operates. The student is first shown a stick, which appears bent, in a bucket of water. This 'appearance' is explained in terms of laws of refraction 
bound up with the intervening medium of water. The next stage is to persuade the student, by analogy, that we have no certain means of discovering the real shape of the stick in what are so-called 'normal' conditions, since there still remains the medium constituted by the cognitive faculties. The inquiry is then shifted towards a search for 'things as they really are', without any interference from the medium.

Hegel's objections to this practice are as follows:

If we remove from a formed thing what the instrument has done to it, then the thing in this case the absolute - is once again just what it was before this obviously superfluous effort.... Or if the examination of knowing, which we represent to ourselves as a medium, makes us acquainted with the law of light refraction in the medium, it is likewise useless to subtract this factor from the result. For knowledge is not the refraction of the ray, but rather it is the ray of light itself; if this be subtracted, we would be left with no more than an indication of pure direction or empty place. (PG.MM.69/B.132)

The point of Hegel's objection is that the absolute is not something apart from, and independent of, the activities in which we are said to possess knowledge. This was already hinted at in a sub-clause when he said that the absolute is not mediated by a means but is 'in and for itself, already close to us of its own accord' (PG.MM.69/B.132). ${ }^{30}$ For in the case of philosophy, and indeed the other sciences too, the means of knowing is internally related to the absolute. Critical philosophy is therefore faulted for having a theory of knowledge dependent upon the assumption of subjective conditions which act as an intervening medium between the knower and the absolute, distorting one's view of the latter. This can, and often does, lead to a lack of interest in the absolute and a turning away from the problems of philosophy towards a study of the mechanics of the cognitive faculties - or language, if the critique is of language rather than thought - the province of psychology or linguistics. 'For nothing,' as Hume says, 'is more certain, than that despair has the same effect upon us as enjoyment, and that we are no sooner acquainted with the impossibility of satisfying any desire than the desire itself vanishes. When we see that we have arrived at the utmost extent of human reason, we sit down contented. ${ }^{31}$

The critical philosopher, however, does not have to concede that the organon distorts knowledge, since he can retain the above assumptions, admitting, as Kant does, that there is no concept of knowledge that can be arrived at without recourse to the subjective faculties. All knowledge is, in this way, ultimately subjective, as shown by the Kantian principle of the synthetic unity of apperception. So when the critical philosopher treats knowledge as something 
mediated by an instrument or medium, he implies that the conditions in which knowledge is possible are determined by the instrument or medium. According to this account of critical philosophy, the organon - being either a medium or instrument - actually produces the world within which reality can appear. As such, it can be argued that the organon does not conceal knowledge - on the contrary, it discloses it. This argument is put forward by Habermas, who argues that it now appears that Hegel is wrong to say that critical philosophy "presupposes that the absolute stands on one side and that knowledge, though it is on the other side, for itself and separated from the absolute, is nevertheless something real'(PG.MM.70/B.133). For here, says Habermas, Hegel is accusing the critical philosopher of postulating an absolute relation between the knowing subject and its object in which a mediating organon can only be seen as a means of distorting what is known. Hegel, he says, is operating on the principle that knowledge and the absolute are one, but the critical philosopher can reply that this need not be so, since what is known is created by the organon and anything outside the limits of the organon is unknowable, or as Wittgenstein of the Tractatus would say, unsayable. This, as we have argued, is not to say that knowledge of the absolute is meaningless: both Kant and Wittgenstein, for example, recognised its importance; the former examining reason to make room for faith, the latter acknowledging the 'depth' of man's urge to 'transcend the limits of language'. But both placed the absolute outside the range of rational inquiry and, as such, cannot be criticised from a standpoint which presupposes its attainment.

But is Hegel operating from a meta-standpoint which presupposes the attainment of absolute knowledge? Referring to the above argument that the organon creates reality rather than obscures it, Habermas concludes :

Only presupposing that reality as such simply appears can this or that individual real element be obscured - unless we presume an absolute relation between reality and the cognitive process that is independent of that instrument. But from the presuppositions of transcendental philosophy we cannot even meaningfully talk of knowledge without identifying the conditions of possible knowledge. Accordingly Hegel's critique does not proceed immanently. For his objection to the organon theory of knowledge presupposes just what this theory calls into question: the possibility of absolute knowledge. ${ }^{32}$

However, in Hegel's defence it must be pointed out that Hegel was not arguing from meta-standpoint. This is to misunderstand the nature of the absolute and Hegel's phenomenological method. His argument was that absolute knowledge (philosophy) is bound up with any system of knowledge, and that critical philosophy itself 
presupposes knowledge of the absolute when it places it outside the range of the organon. (For what is the criterion for determining the extent of the organon other than the presupposition of absolute knowledge?) Hegel does not presuppose absolute knowledge himself; he only has to expose the metaphysical assumptions of critical philosophy. And his faulting of critical philosophy requires no standards other than those employed by the critical philosopher himself, as we shall see in the following section.

\section{THE PRESUPPOSITIONS OF CRITICAL PHILOSOPHY}

Hegel's criticism of the critical philosophy is ultimately justified because he can point to certain unfounded presuppositions within the critical method, upon which rests the standard for determining the bounds of sense/limits of language. Both Kant and Wittgenstein of the Tractatus assumed that the world could be represented in only one way, and accordingly they sought the standard for determining the correctness of this representation. This is precisely the issue Hegel seizes upon. The critical philosopher has definite ideas about the nature of his critique. How are they justified? Kant himself said a great deal about the organisation of the cognitive faculty as the essential unity of the transcendental conditions under which language has sense; but by what right did he specify these conditions?

Both Wittgenstein and Kant specified these conditions by a priori means, and in doing so revealed an affection for a particular prototype of knowledge.

\section{A. Wittgenstein}

Wittgenstein, for instance, assumed that the ultimate standard lay in a similarity of structure between that which pictures and that which is pictured. Accordingly there was only one logical form of language. A critique of language placed the traditional metaphysical subjects of God, the Soul, and so on, outside the limit of language. Even the critique itself lay outside the limit of what could be said. Language, argued Wittgenstein, can no more describe its own essence than it can describe the essence of that which it pictures.

As Russell states, however, in his Introduction to the Tractatus:

What causes hesitation is the fact that, after all, Mr. Wittgenstein manages to say a good deal about what cannot be said, thus suggesting to the sceptical reader that possibly there may be some loophole through a hierarchy of language. (TLP.p.xxi) 
To meet this objection, Wittgenstein conceded that the whole programme consists in saying the unsayable, but this he justified on the grounds that his 'elucidations' must be used and discarded, like a ladder one must throw away after scaling it (TLP.6.54).

Wittgenstein, however, was to express dissatisfaction with this transcendental standpoint, though at the time of writing the Tractatus he had no reservations in this respect. The transcendental nature of the Tractatus 'elucidations' is bound to the famous 'picture theory', which states that only genuine propositions are those which have truth poles. The proof of this claim, however, does not have truth poles and therefore lies outside the realm of genuine discourse. The picture theory can only be justified on transcendental grounds, and assumptions that language has a self-evident Verbindung with reality. ${ }^{33}$ Accordingly, language could be examined by a priori means in a once and for all attempt to determine its essence. But as the whole thing rests on a transcendental base, by what right does it assert superiority over other equally transcendental theories?

As Miss Anscombe points out, the Tractatus theory, if true, would be the death of natural theology because the propositions of the latter are held to be true in such a way as to deny the possibility of the truth of their opposite. ${ }^{34}$ Equally, it could be said that from the standpoint of natural theology the Tractatus theory is invalid, since it can be contradicted by the self-evident truths of natural theology. Who is correct? What we have is a clash of standards, neither of which has the right to the claim of obvious truth. This may be the way in which knowledge does manifest itself but, if so, we cannot give much weight to a critique of its foundations, since we have nothing at the base but unfounded presuppositions.

In a very important sense, any other coherent metaphysical system could reject the Tractatus on the grounds that it does not accord with certain transcendental truths of its own. This is Hegel's point in arguing that critical philosophy presupposes certain standards whose validity is problematic if one adopts a critical approach. When the critical philosopher seeks to rule out another system of knowledge as nonsensical (e.g. natural theology from the standpoint of the 'picture theory'), by what right, asks Hegel, other than the force of his assurance, does he claim to have proved the other to be nonsensical?

For science cannot simply reject an untrue form of knowledge as a merely common view of things and give assurance that it is a completely different way of knowing, to which the other knowledge is of no significance whatever. Nor can it refer to the intimation of a better knowledge within that other. By giving this assurance it would 
declare that its force resides in its being; but the untrue knowledge also appeals to the fact that $i t$ is, and gives assurance that to it science is nothing - one barren assurance carries as much weight as another. (PG.MM.71/B.134-35)

\section{B. Kant}

Kant, too, based his critique on standards which he held to be unproblematic. In particular, he held to a conception of scientific method popular from the time of Descartes - the principle of universal doubt - which Hegel expresses as

the resolve not to found science on authority, surrendering oneself to the thoughts of others, but rather to examine everything for oneself and follow only one's own convictions, or, better yet, to produce everything by oneself and hold one's own act to be true. (PG.MM.73/B.136)

From Descartes to Kant, the principle of doubt required no justification because it was held to be the very essence of the faculty of reason. For Descartes, the existence of the self was guaranteed by the ability to doubt. For Kant, nothing was more certain than the 'I think' which accompanied his representations. ${ }^{35}$ Methodical doubt and the doubting self were intimately bound up with each other and were thus held to be unproblematic. The critique of knowledge was founded on a specific conception of science and the knowing subject. The ultimate court of appeal was to the knowing subject which possessed within itself the laws of reason. But, as Habermas points out: 'These are assertions claiming self-evidence that are no longer convincing today as basic assumptions of rationalism. Radical doubt that needs to be neither justified nor learned through practice is no longer conceded a transcendental role. At most it has a role in cognitive psychology. ${ }^{36}$ Nowadays the scientific method associated with methodical doubt is simply one more belief amongst others, but formerly it was seen as the ultimate standard of reason. In this way, the Kantian critique, basing itself upon a programme of methodical doubt, was seen by Hegel to rest on nothing more than a 'barren assurance', and Kant was faulted for elevating it to a transcendental certainty.

Now making methodical doubt the principle of the critique reveals that the key presupposition of critical philosophy is of a specific concept of science. As Habermas says:

From the very start the enterprise of a critique of pure speculative reason assumes the normative cogency of a specific category of knowledge. Presupposing that the statements of mathematics and contemporary physics are valid as reliable knowledge, the 
critique of knowledge can take principles that have proved themselves in these processes of inquiry and use them to draw conclusions about the organisation of our cognitive faculty. ${ }^{37}$

This can be seen in the way Kant spoke of the 'sure mark of science' (where science means Newtonian science) against which we find Hegel arguing, in the Preface to the Phenomenology, that the standards of mathematics and physics, which have proved themselves in their own fields, should not be used to provide the foundation for other areas of knowledge, least of all the organisation of the cognitive faculties. Kant, of course, was heavily influenced by the natural sciences, so much that he saw its methods to be transcendental and free from presuppositions. But, as Hegel argues, to achieve, this freedom and to avoid the logical circle of 'knowing before you know', he must begin with an undemonstrated criterion of the transcendental validity of scientific judgments. This criterion, as we have seen, evoked from Hegel the comment that 'one barren assurance carries as much weight as another'.

Hegel is not saying that scientific methods are unwarranted. $\mathrm{He}$ is saying that they do not rest on transcendental base. Science itself is not barren - only the claim that a particular methodology, divorced from its content, is valid for all forms of knowledge. Because the critique must have no standard excused from examination, a scientific method, like any other standard, must not be employed before it is justified. Thus, taking the critique at its own word, using no standard other than the critique's own standard of methodical doubt, we (Hegel and his reader) are to refrain from any prejudgment about scientific truth. The method employed must be sceptical, and the critique must be used unsparingly against itself.

The path towards absolute knowledge, which is beginning to emerge from Hegel's account of critical philosophy, must embrace a total scepticism with regard to any foundations of knowledge. This is what Hegel has in mind when he says 'The road may thus be viewed as a way of doubt or, more properly, as the way of despair' (PG.MM.72/B.135). This scepticism, however, is derived from the critique itself. Hegel is bringing in no other standard than that derived from the critique. By taking the critique seriously, he is achieving the break with natural consciousness without having to invoke standards of his own. The standard he does seize upon, however, is the principle of radical doubt. Because the critique must have no standard excused from examination, none of the presuppositions of natural consciousness can be employed before their justification. Such a justification leads only to the logical circle of 
'knowing before you know'. The alternative is to adopt a programme of radical scepticism, which will destroy the standpoint of critical philosophy.

Hegel does not attempt to avoid this scepticism; his purpose is only to describe. Unlike most philosophers, however, he sees in this very scepticism the possibility of achieving the required breach with natural conscicusness. Scepticism is not a completely negative exercise. If the sceptic learns that those assumptions given as 'natural knowledge' are ultimately relative, then something positive will have been achieved. The sceptical route, or the 'highway of despair', as Hegel calls it, is the direction in which the understanding of absolute truth is attained. For it is through that

scepticism which directs itself to the whole compass of phenomenological consciousness in its manifestations that Spirit becomes able, for the first time, to examine what truth is. For this scepticism brings about a despair over concepts, thoughts and opinions which are called natural, and it is of no consequence whether these notions are said to be one's own or others. (PG.MM.73/B.136)

The hold of natural consciousness is broken when it is realised that one can doubt (and by implication demand justification for) any theory which holds that one valid way of representing the world is superior to any other. So when Hegel applauds scepticism, it is not merely the scepticism of a Hume or a Descartes, but a scepticism directed at the presuppositions built into their epistemological and ontological theories. Which one can we believe, he asks, when each competing epistemology has as much worth as another? Only by asking this question does spirit, as Hegel says, become able 'to examine what truth is'. The truth lies not in some transcendental sphere, but is relative to the various means of determining it.

It is in this way that the critique becomes a weapon of its own destruction. The knowing consciousness, which is the object of the epistemologist's inquiry, has no built-in categories that can be examined as a precursor to their employment. Nor does it have access to an unproblematic standard of certainty. In a state of radical doubt, the critical consciousness is relegated to what Hegel describes as 'phenomenological knowledge'. The suspension of any favoured prototype of knowledge does not mean that one should lapse into the dogmatism of commonsense, or seek certainty in the existence of a knowing cogito. 'It matters little', says Hegel, 'whether one bases himself on the authority of others or on personal conviction; the only difference is the vanity peculiar to the latter' (PG.MM.73/B.136). The investigation and critical examination of the reality of human knowledge cannot take place without 'some presupposition which will serve as the fundamental standard of 
measurement' (PG.MM.73/B.139). We therefore leave the critical consciousness ready to examine the various forms of knowledge but, ironically, 'where science will make its first appearance, neither science nor anything else has justified itself as the essence or as the in itself; and without some basic principle, it seems that an examination cannot take place' (PG.MM.75-76/B.139). Hegel's alternative to the foundational approach, in this way, has its genesis in the ruins of traditional epistemology. We must therefore pause to consider the alternatives to traditional epistemology before pursuing our investigation into Hegel's answer to the question 'What are the consequences of a non-foundational approach to the problems of philosophy and the sciences?'

\section{NIETZSCHE'S ANSWER: PERSPECTIVISM AND THE DENIAL OF THE ABSOLUTE}

The weakness of the critique as a preliminary to the attainment of absolute knowledge was astutely recognised by Nietzsche who, like Hegel, saw that a critique involves presuppositions which cannot be questioned without self-destruction:

Deeply mistrustful of epistemological dogmas, I loved to look first out of one window and then out of another, keeping myself from immunising myself in them, for I considered this harmful - and finally, is it likely that a tool can criticise its own fitness? - What I paid attention to, rather, was that no epistemological scepticism or dogmatism ever came into being without ulterior motives, and that these doctrines decline in value as soon as one considers what really forced them into this position. Basic insight: Kant as well as Hegel or Schopenhauer - the sceptic-epochistic as well as historicizing or pessimistic - are of moral origin. ${ }^{38}$

Nietzsche appears to be using arguments similar to those used in Hegel's own attempt to bar entry into a theory of knowledge. He rightly argues that the organon model must ultimately collapse into an inability to define itself:

One would have to know . . . what certainty is, what knowledge is, and so forth. But since we do not know this, a critique of the cognitive faculty is absurd. How could the instrument criticise itself, if it can use only itself for this critique? It cannot even define itself. $^{39}$

But Nietzsche has a different motive for rejecting the critique than Hegel. The latter employed this argument to achieve a 'redirection of natural consciousness', and the rejection of a critique was the first step in his attempt to reveal the nature of absolute knowledge. It must therefore be distinguished from Nietzsche's application of the 
argument to deny the possibility of genuine knowledge in the face of subjectivist interpretations. For example:

As long as the word 'knowledge' has any meaning at all, the world is knowable. But it can be interpreted differently; it does not have a meaning behind it, but inummerable meanings. - 'Perspectivism'. It is our needs that interpret the world; our instincts and their pro and con. ${ }^{40}$

As we can see, Nietzsche was unable to free himself from certain positivistic assumptions about the relationship between the world and human knowledge. The world is a collection of facts, which can be interpreted this way or that according to needs or instincts. How the world is independent of these needs is a mystery that can never be solved. So, by 'perspectivism', Nietzsche means only the particular subjective perspective based on needs and instincts. ${ }^{41}$ Speaking of what he calls the 'objectivist aberration', he argues, from within his positivistic standpoint, against the possibility of ever attaining a genuine truth:

The aberration of philosophy comes from this: instead of seeing logic and the categories of reason as means to the adaption of the world to ends of utility (that is, in principle', for a useful falsification), man believe to possess in them the criterion of truth or reality. The 'criterion of truth' was in fact merely the biological utility of such a system of falsification. And since an animal species knows nothing more important than preserving itself, one may in fact speak of 'truth' here. The naiveté was only to take this anthropocentric idiosyncrasy as the measure of things, as the judge of 'real' and 'unreal' - in short, to make absolute what is conditioned. ${ }^{42}$

The attachment of truth is merely a biological convenience. As such, any claim to the truth will suffice as long as we can put forward some needs to justify it. In this way, Nietzsche's criticism of the organon theory of knowledge passes into the very kind of subjectivity and relativism that Hegel wished to avoid. Nietzsche's attempt to 'go beyond Kant' led him to abandon the hope of ever attaining an understanding of the truth, which is exactly what Hegel warned against when he said:

When thought grows hopeless of ever attaining, by its own means, the solution of the contradictions which it has by its own actions brought upon itself, it turns back to those solutions of the question with which the mind had learned to pacify itself in some of its other modes and forms. Unfortunately, however, the retreat of thought has led it, as Plato noticed even in his time, to a very uncalled for hatred of reason; and it then takes up against its own endeavours that hostile attitude of which an example is seen in the doctrine that 'immediate' knowledge, as it is called, is the exclusive form in which we become cognisant of the truth. (Enz.I.11) 
It is clear that if Hegel is to avoid the presuppositions that are built into the foundational approach, he must also avoid the pitfalls of subjectivity and relativism which characterise Nietzsche's alternative to the theory of knowledge. In the following chapter, we shall seek Hegel's solution to this problem as we continue with our analysis of the Introduction to the Phenomenology. 